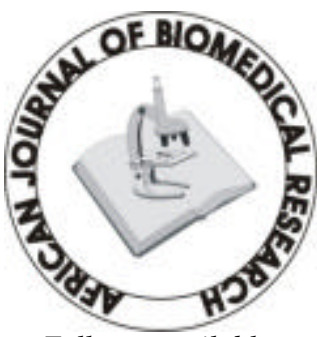

Full-text available at http://www.ajbrui.com http://www.bioline.br/md http://www.ajol.com

Received:

December 2006

Accepted (Revised) : May 2007

Published

September 2007
Short communication

\section{Prevalence of Some Uropathogenic Bacterial Isolates and their Susceptibility to Some Quinolones}

\author{
Idowu A.O ${ }^{*}$ and Odelola H.A. ${ }^{+}$ \\ Department of Pharmaceutical Microbiology, \\ Faculty of Pharmacy, Olabisi Onabanjo University, \\ Sagamu, Ogun State, Nigeria. \\ + Department of Pharmaceutical Microbiology, \\ Faculty of Pharmacy, University of Ibadan, Nigeria.
}

\section{ABSTRACT}

Bacterial Isolates of different Genera were collected from suspected cases of Urinary tract infection in Ibadan and their prevalence was determined. Sensitivity pattern of the organisms to quinolone antibacterial agents was also investigated by the antibiotic disc diffusion method using Kirby Bauer method. The study revealed the prevalence of uropathogenic organisms as follows:- Escherichia coli (46.2\%), Klebsiella spp (23.1\%), Staphylococcus aureus $(21.1 \%)$ and Pseudomonas aeruginosa (9.6\%). The quinolones were found to be highly effective against all the organisms. The average percentage susceptibility of the organisms were as follow: Staphylococcus aureus (92.7\%) Escherichia coli (81.7\%), Pseudomonas aeruginosa (76.0\%), and Klebsiella spp $(70.0 \%)$. As indicated by their high activity, quinolones are better alternatives to commonly prescribed antibiotics in Urinary tract infection therapy although caution must be exercised in their prescription as the emerging low level of resistance may portend great danger for their future use. (Afr. J. Biomed. Res. 10: 269 - 273)

Key words: - Uropathogenic, Bacterial Isolates, Prevalence, Susceptibility, Quinolones

*Address for Correspondence: Phone: +234-08027348864; solaid2002@yahoo.com

Abstracted by:

African Index Medicus (WHO), CAB Abstracts, Index Copernicus, Global Health Abstracts, Asian Science Index, Index

Veterinarius, Bioline International , African Journals online 


\section{INTRODUCTION}

Generally, there is agreement among the various authors in the literature that the predominant uropathogens acquired from any source are Gram negative bacteria with Escherichia coli accounting for the highest prevalence in most instances (Gupta et al 1999, Huda et al 2003, Moges et al 2002) Gram positive organisms including Enterococcus spp and coagulase negative staphylococci are also frequently involved (Moges et al 2002).

Antibiotic resistance of urinary tract pathogens has been known to increase worldwide, especially to commonly used antimicrobials. (Gordon et al 2000, Gupta et al 1999, Kahlmeter 2003, Mazzuli 2002 ). The antibiotic sensitivity patterns of either one or more of the organisms have been determined to one or more of the commonly used antimicrobial drugs in Urinary Tract Infection (UTI) cases (Gordon et al 2000, Gupta et al 1999, Huda et al 2003, Kahlmeter 2003).

There is need therefore to evaluate the activity of newer antibiotics against the organisms so as to determine the best option in therapy and to monitor incidence of resistance. This study investigates the prevalence rate and antibiotic sensitivity patterns of urine pathogens to quinolones

\section{MATERIALS AND METHODS}

\section{Bacteriology}

Fifty two cultures of clinical isolates of different uropathogenic bacteria isolated from urine in suspected cases of urinary tracts infection were collected from the University College Hospital (UCH), Catholic Hospital, Oluyoro and State Hospital, Ring Road all in Ibadan. The isolates were subjected to established characterization methods to confirm their identity (Cowan 1974). All the bacterial isolates were preserved on nutrient agar slants at $4^{\circ} \mathrm{C}$ and subcultured periodically

\section{Antibiotic Sensitivity Tests}

Antibiotic sensitivity tests was performed by the antibiotic disc diffusion method of Kirby-

Bauer on Mueller-Hinton agar plates using the following quinolone antibiotics

Norfloxacin (10mcg) (Cadila, India)

Perfloxacin (5mcg) (V.S. International, India)

Ciprofloxacin $(5 \mathrm{mcg})$ (V.S. International India)

Ofloxacin (5mcg) (ZMC, China)

Sparfloxacin (10mcg) (Wockhardt, India). They were all locally obtained. The culture plates were incubated at $37^{\circ} \mathrm{C}$ for $24 \mathrm{hrs}$ after which the zone of growth inhibition was measured to the nearest millimeter.

The results were interpreted using the antibiotic disc's manufacturers' standard table that relates diameter of zone of inhibition to the degree of microbial resistance

\section{RESULTS}

The study involved a total of 52 urinary tract infection isolates. The prevalence rate of uropathogenic organisms was found to be in the order of Escherichia coli (46.2\%), Klebsiella spp (23.1\%), Staphylococcus aureus (21.1\%), Pseudomonas aeruginosa (9.65\%). (Table 1).

Table 1

Prevalence rate of uropathogenic organisms in Ibadan.

\begin{tabular}{lll}
\hline Organism & Number & Percentage \\
\hline Escherichia coli & 24 & 46.2 \\
Klebsiella species & 12 & 23.1 \\
Staphylococcus aureus & 11 & 21.1 \\
Pseudomonas aeruginosa & 5 & 9.6 \\
\hline Total & 52 & 100.0 \\
\hline
\end{tabular}

Table 2 shows the susceptibility pattern of the isolated uropathogenic organisms to all the quinolones used in this study. All the organisms showed high susceptibility to the quinolones with average percentage susceptibility of Escherichia coli (81.7\%) Klebsiella spp (70.0\%), Staphylococcus aureus (92.7\%) and Pseudomonas aeruginosa $(76.0 \%)$. The level of resistance was higher in the Gram negative organisms while resistance was lowest for Ofloxacin in all the organisms. The susceptibility pattern (Table 2) clearly showed Ofloxacin as the quinolone with the highest activity against all the organisms isolated. 
Table 2

Susceptibility Patterns of uropathogenic organisms to the Quinolones

\begin{tabular}{llllll}
\hline & Norfloxacin & Pefloxacin & Ciprofloxacin & Ofloxacin & Sparfloxacin \\
No of Isolates & No $(\%)$ & No $(\%)$ & No $(\%)$ & No $(\%)$ & No $(\%)$ \\
24 E. coli & $19(79.2)$ & $19(79.2)$ & $19(79.2)$ & $22(91.7)$ & $19(79.2)$ \\
12 Klebsiella spp & $8(66.7)$ & $7(58.3)$ & $8(66.7)$ & $11(91.7)$ & $8(66.7)$ \\
11 S. aureus & $10(90.9)$ & $9(81.8)$ & $10(90.0)$ & $11(100.0)$ & $11(100.0)$ \\
5 P. aeruginosa & $4(80.0)$ & $4(80.0)$ & $4(80.0)$ & $4(80.0)$ & $3(60.0)$ \\
\hline
\end{tabular}

\section{DISCUSSION}

The prevalence of uropathogenic organisms has been remarkably consistent with Gram negative organisms accounting for most infections (Gupta et al 1999, Huda et al 2003, Moges et al 2002).

This study reveals a higher prevalence of Gram negative organisms as causative organisms in UTI cases as evident in the prevalence rates of $46.2 \%$ for Escherichia coli and $23.1 \%$ for Klebsiella spp. This trend is in agreement with previous studies (Huda et al 2003, Moges et al 2002). The implication of these findings is that antimicrobials that have wide Gram negative coverage and are particularly effective against Escherichia coli may be used in the empiric therapy of urinary infections.

Quinolones are being increasingly used in the therapy of urinary tract infections due to wide spread bacterial resistance to commonly used antimicrobials (Catherine et al 2002). In this study, there was a high degree of susceptibility by all the uropathogenic organisms to the various quinolones tested. Resistance was least in Staphylococcus aureus (7.6\%) and highest in Klebsiella spp (30\%). Ofloxacin was clearly the most effective quinolone against the uropathogenic organisms studied.

Two enzymes responsible for bacterial DNA synthesis, DNA gyrase and topoisomerase IV are usually inhibited by quinolones. Resistance to quinolones has been due to enzymes mutational change in the organism providing alteration in target site and loss of potency. (Catherine et al 2002). In Gram negative organisms, alterations in outer membrane porin proteins due to mutations would lead to decrease in permeability through the outer membrane so that less drug reaches the target site (Catherine et al 2002). This may be responsible for the higher rate of resistance for the Gram negative organism compared to Gram positive organisms observed in this study.

Despite the high degree of susceptibility of the bacterial tested to the quinolones there should be concern about the low level of resistance. Some workers using molecular methods to study the mechanism of resistance in floroquinolones reported that their use might become limited by the emergence of resistance (Chen et al 2001). The low level of resistance may become high due to selective pressure of exposure with constant use as a result of drug abuse and arbitrary prescription of these agents.

The high activity of quinolones in this study against urine pathogens suggests that they would continue to be better alternative to the commonly prescribed antimicrobials in cases of UTI. These antibiotics should however be used with caution because of the emerging low level of resistance which may portent great danger for their future use.

\section{REFERENCES}

Catherine MO, Gary MG. (2002) Quinolones: A comprehensive review. America Family Physician. 65: 455 - 64. Retrieved October 2002 from http://www.aafp.org/afp/200020201/455.html

Chen FJ, Mc Donald LC, Ho M, Lo HJ. (2001) Molecular epidemiology of ciprofloxacin reduced susceptibility to Escherichia coli: a herald for emerging resistance. Programme and abstracts of the 
41st interscience conference on Antimicrobial Agent and Chemotheraphy; December 16-19, Chicago Illinois. Abstract 2113

Cowan, S.T. (1974) Cowan and Steel's Manual for the identification of Medical Bacteria, $2^{\text {nd }}$ edn. Cambridge University Press, Cambridge, p. 47-49.

Gordon KA, Jones RN, (2003) Susceptibility patterns of orally, administered antimicrobials among urinary tract infection pathogens from hospitalized patients in North America; comparison report to Europe and Latin America. Results from the sentry Antimicrobial Surveillance Programme (2000). Diagn Microbiol infect Dis 45; 295-3001. Abstract.

Gupta K, Scholes D, Stamm W. (1999): Increasing prevalence of antimicrobial resistance among uropathogens causing acute uncomplicated cystitis in women JAMA; 281:736 - 738 Abstract.

Huda AB, Ibrahiem MS. (2003): Antimicrobial Resistance among pathogens causing acute uncomplicated UTIs. Retrieved May 2003 from www.medscape.com/view article/410 1825
Kahlmeter G. (2003) An international survey of the antimicrobial susceptibility of pathogens from uncomplicated urinary tract infections; the ECO. SENS Projects. J. Antimicrobials chemother 51: 69- 71 Abstract.

Mazzuli T. (2002) Resistance trends in urinary tract pathogens and impact on management. J. Urol 168; 1720-2 Abstract.

Moges AF, Genetu A, Mengistu G. (2002): Antibiotic sensitivities of common bacterial pathogens in urinary tract infections at Gondar Hospital, Ethiopia. East Afr Med J; 79: 140-2. Abstract.

Reid G, Seidenfeld A. (1997): Drug resistance amongst uropathogens isolated from women in a suburban population: laboratory findings over 7 years. Can J Urol; 4432 - 437. Abstract.

Stratton C. (2001): Fluoroquinolone Resistance in UTIs: The Next Big Problem? Programme and abstract of the 41st interscience conference on Antimicrobial agents and chemotherapy: December 16-19, Chicago, IIIinois. Abstract. 